\title{
Functional Hemispherectomy for Adult Rasmussen Encephalitis: A Case Report and Literature Review
}

\author{
Qun WANG ${ }^{1}$, Zhanpeng ZHU², Guangming WANG², Lichao SUN³*, Jiqing QIU²* \\ ${ }^{1}$ Hiser Hospital, Department of Neurology, Qingdao, China \\ ${ }^{2}$ The First Hospital of Jilin University, Department of Neurosurgery, Changchun, China \\ ${ }^{3}$ The First Hospital of Jilin University, Department of Emergency Medicine, Changchun, China \\ *Lichao SUN and Jiqing QIU contributed equally to this work.
}

Corresponding author: Lichao SUN, Jiqing QIU sunlichao5@sina.com, qiujiqing2008@126.com

\section{ABSTRACT}

Rasmussen encephalitis (RE) is a rare and severe brain disorder that is associated with unilateral hemispheric atrophy and manifests as severe refractory epilepsy, hemiplegia, defects of motor and speech functions, and cognitive impairment. Treatment of RE, especially in adult patients, is extremely challenging. Herein, we report the case of an adult patient with RE who was treated with a functional hemispherectomy and achieved a favorable prognosis. A 29-year-old woman presented with a 24-year history of epileptic seizures. Neurological examination showed hemiplegia, homonymous hemianopsia, and right muscular atrophy. Neuropsychological examination demonstrated cognitive disorders. Serial magnetic resonance imaging (MRI) and computed tomography (CT) scans showed progressive encephalatrophy in the left hemisphere and ventriculomegaly in the left lateral ventricle. The Wada test showed that the right hemisphere was dominant for language. A functional hemispherectomy was performed. Postoperatively, no antiepileptic drugs were administered, and the patient remained seizure-free without aggravation of hemiplegia. Over a 2-year follow-up, cognitive functions improved. In an adult patient with RE, a favorable prognosis was achieved after functional hemispherectomy. The safety and efficacy of functional hemispherectomy in patients with RE is highlighted.

KEYWORDS: Epilepsy, Hemispherectomy, Rasmussen encephalitis, Surgery

\section{INTRODUCTION}

$\mathrm{R}$ asmussen encephalitis (RE), also known as Rasmussen syndrome, is a rare, progressive type of epileptic syndrome caused by chronic idiopathic inflammation of a brain hemisphere $(4,6)$. The clinical characteristics include severe refractory epilepsy, hemiplegia, defects of motor skills and speech, dementia, and encephalitis-inflammation of the brain with progressive atrophy of one cerebral hemisphere. RE usually involves a unilateral cerebral hemisphere and most commonly affects young children, with a reported average age at onset of 6 years $(2,4,8)$. New RE diagnosis in adulthood is rare. The incidence of RE is reported to be approximately $1.7 / 10$ million, and the annual prevalence rate is $0.18 / 100,000$ in children up to age 16 years (9). The influences of gender, geographic location, and ethnic differences on the morbidity and prevalence of RE have yet to be identified. Due to its extensive involvement and progressive clinical course, treatment of RE is extremely challenging, and the prognosis is unfavorable.

Hemispherectomy for infantile seizures and hemiplegia has been in use for nearly 80 years since it was first performed by McKenzie in 1938 (13). The main indication for this procedure is an extensive hemispheric lesion with hemiplegia and refractory epilepsy. Hemispherectomy includes two main subtypes: anatomical and functional-the former refers to removal of the entire hemisphere, whereas the latter refers to

\footnotetext{
Qun WANG (1): 0000-0003-3614-2636

Zhanpeng ZHU (1): 0000-0001-5419-4507

Lichao SUN (1) : 0000-0003-2452-045X

Guangming WANG (1) : 0000-0002-3736-8904

Jiqing QIU (1) : 0000-0003-4056-0937
} 
a resection of epileptic portions of the involved hemisphere. In the published literature, functional hemispherectomy has been widely attempted in pediatric cases of RE $(3,15)$; however, its safety and efficacy in adult RE patients remain undetermined. Herein, we report the case of an adult patient with RE who was treated with a functional hemispherectomy and achieved a favorable prognosis.

\section{- CASE REPORT}

A 29-year-old woman presented to us with a 24-year history of convulsions. These convulsions originally manifested as at witching of the right thumb that extended to the right hand and later to the entire upper limb. These seizures occurred once every 1 to 2 months, and documented episode durations ranged from a few minutes to 24 hours. During these episodes, the patient experienced reversible hemiplegia and speech disorders. At age 5, the patient was diagnosed with Jacksonian seizure and treated with carbamazepine, with no significant improvement. Just before hospitalization at our institute, the patient had 1-2 seizures daily and was on phenobarbital (180 mg/day). The patient had neither history of prenatal disease, febrile convulsion, or head trauma nor a family history of epilepsy.

Neurological examination showed a complete right homonymous hemianopsia. Muscle strength in the right lower extremity, the proximal upper extremity, and the distal upper extremity was grade 4, 3, and 0 , respectively. Additionally, high muscle tone, deep-tendon hyperreflexia, and muscular atrophy-especially of the thenar muscles-were noted in the right limbs. Babinski's sign was positive in the right extremity. Neuropsychological examination demonstrated cognitive disorders, manifesting as delusion and memory loss. Intellectual evaluation according to the Wechsler Adult Intelligence Scale Revised by China (WAIS-RC) revealed a verbal intelligence quotient (IQ) of 55.62, and a performance IQ of 52.33 .

Serial magnetic resonance imaging (MRI) and computed tomography (CT) scans showed progressive encephalatrophy of the left hemisphere and ventriculomegaly of the left lateral ventricle (Figure 1A-F). Video electroencephalography (EEG) showed disappearance of the a-rhythm in the left occipital lobe. Interictal EEG showed a sporadic spike and slow waves in the left hemisphere. During the ictal period, EEG revealed a cluster of spike waves originating from both hemispheres and then evolving into slow waves (Figure 2A-C). The Wada test indicated that the right hemisphere was dominant for language, and the results of routine laboratory tests were all normal. A diagnosis of RE was made based on the diagnostic criteria proposed by Bien et al. in 2005 (2), and a functional hemispherectomy under general anesthesia was planned. The postoperative histopathological analysis showed multifocal cortical inflammation, neuronal loss, and gliosis. Perivascular leukocyte aggregation and neuronal necrosis also were observed.
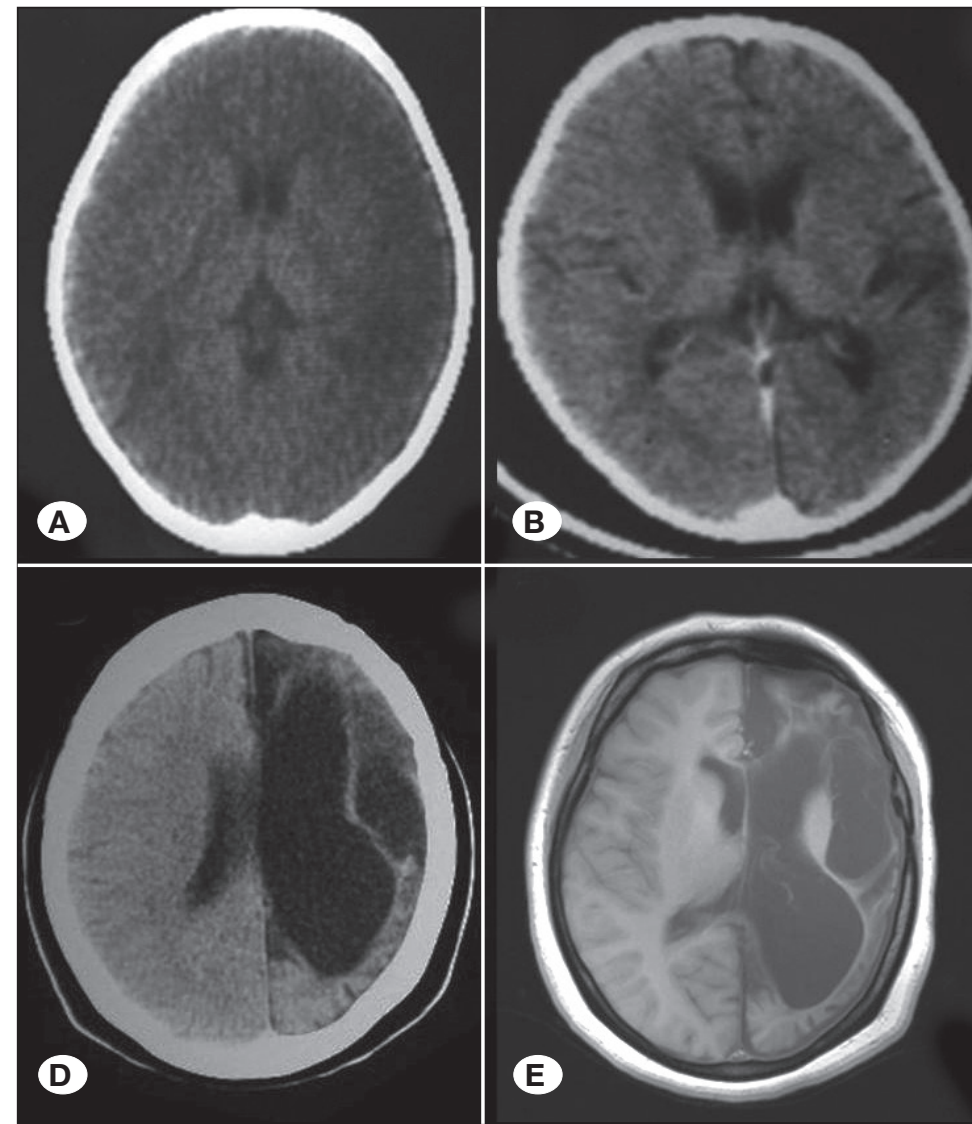
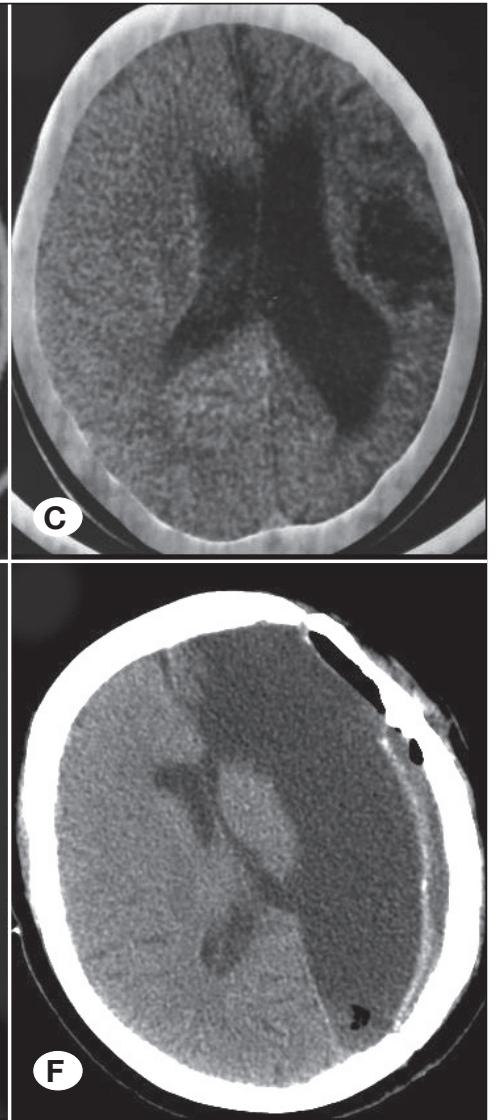

Figure 1: Serial neuroimaging of the patient with RE. Brain CT at ages 5 (A) and 6 (B) showed hypointensity in the left hemisphere. Brain CT at ages 10 (C) and 12 (D) revealed progression of the left hemispheric lesion. At age 29, a brain MRI (E) showed a more significant encephalatrophy in the left hemisphere and ventriculomegaly in the left lateral ventricle. Postoperative CT (F) shows that the left hemisphere has been removed. 


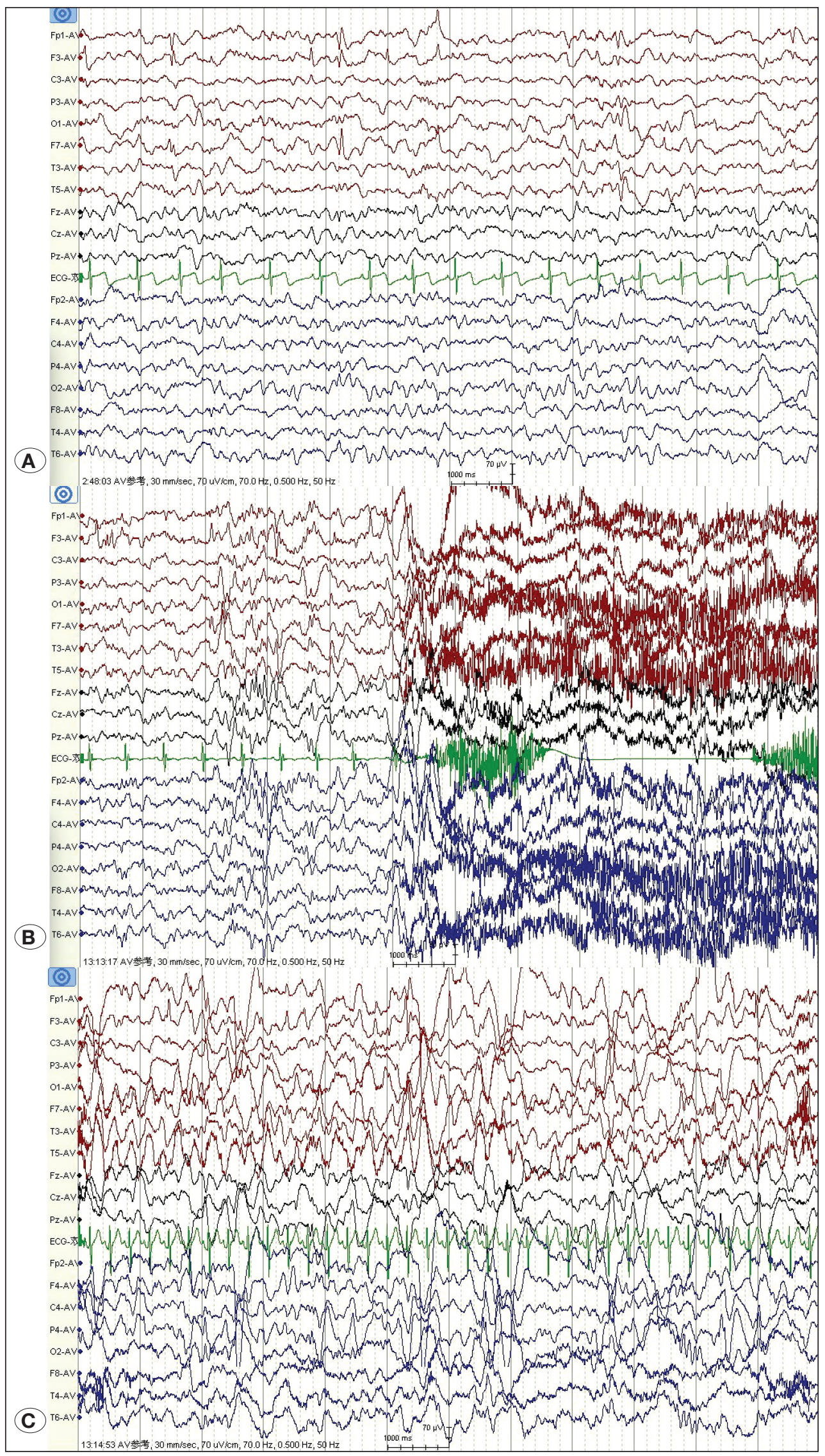

Figure 2: EEG of the patient with RE. A) The background of the EEG showed that a-rhythms of the left occipital area disappeared and the amplitude was lower than that in the right occipital area. Interictal EEG showed sporadic spike-slow waves in the left frontotemporal lobe. B,C) Ictal EEG showed a cluster of spike waves originating from both hemispheres, which evolved into slow waves. 
Postoperatively, no antiepileptic agent was administered, and the patient remained seizure-free (Engel class I), without aggravation of hemiplegia. At a routine follow-up after 2 years, the patient's verbal and performance IQ were 64.36 and 66.67 , respectively.

\section{DISCUSSION}

In 1958, Theodore Rasmussen first described RE (11). This syndrome is a rare acquired inflammatory encephalopathy characterized by progressive atrophy of a single brain hemisphere. Typical manifestations comprise drug-resistant partial seizures and progressive neurological and cognitive defects $(1,7)$.

The etiopathogenesis of RE has yet to be elucidated, but some researchers have observed similarities between RE and the Russian spring-summer meningoencephalitis caused by a flavivirus infection $(1,7)$. Furthermore, there are relevant studies wherein genes pertaining to Epstein-Barr (EB), varicella zoster, cytomegalovirus, and herpes simplex viruses have been detected in RE brain tissue specimens; however, there is, at present, no conclusive evidence confirming viral infection as a contributor in RE etiopathogenesis, and further studies involving a large-scale cohort are needed $(7,10,14,16)$. Additionally, there are studies suggesting an immune basis, wherein glutamate receptor 3 (GluR3) autoantibodies and T lymphocytes may be associated with RE pathogenesis $(12,17)$.

The diagnosis of RE may be challenging as this condition is usually unremarkable on neuroimaging in the early stages, whereas serial MRI and CT scans can show evidence of gradual atrophy of brain substance in tandem with the development and progression of RE (6). EEG presentations are usually nonspecific, and suggestive characteristics facilitating diagnosis include: impairment of background activity, spike waves during sleep, focal slow waves, and multifocal ictal discharges.

The most common clinical manifestation of RE is frequent simple partial motor seizures, which is consistent with the form of epilepsia partialis continua (EPC). Notably, epileptic seizures in RE patients are usually refractory to antiepileptic drugsnamely, medically intractable (3). Neurological deterioration can be manifested as progressive hemiparesis, hemianopia, cognitive disturbance, and, if the language dominant hemisphere is affected, aphasia. Therefore, the main goals of treatment for RE patients include alleviation of epileptic seizures and preventing further deterioration/progressive neurological deficits. As antiepileptic drugs are usually ineffective, surgical treatment has played a major role in the treatment of RE. Initial surgical strategies include focal resection and multiple subpial transections; nevertheless, these procedures have not shown significant efficacy (15).

Recently, functional hemispherectomy has received widespread acceptance as an effective method for seizure control and for the prevention of neurological and cognitive deterioration. As reported, the control rate of epileptic seizures could reach $70 \%$ to $80 \%$ during long-term follow-up in patients with RE after a functional hemispherectomy (3).
Another controversy lies in the timing of surgery (15). Some scholars recommend early surgery, prior to the development of irreversible neurological impairment; additionally, in early childhood, systemic rehabilitation postoperatively may help rescue neurological function. However, there is a counterview that a functional hemispherectomy may induce more severe neurological damage, such as hemiplegia, hemianopia, and aphasia (if the dominant hemisphere is removed). Considering cortical plasticity, functions of the impaired hemisphere may have been remodeled in the contralateral hemisphere. Bulteau et al. observed speech function recovery following removal of the left injured dominant hemisphere (5). Thus, we recommend early surgery for patients with RE.

In the current case, we noted that language dominant domains have been remodeled in the right hemisphere, and after a functional hemispherectomy both language function and motor functions of the right extremities underwent no further deterioration. During a 2-year follow-up period, the patient was seizure-free and showed improvements in intellectual functions. Therefore, functional hemispherectomy may be effective for adult patients with RE.

\section{- CONCLUSION}

In an adult patient with RE, a favorable prognosis was achieved after functional hemispherectomy. The safety and efficacy of a functional hemispherectomy in patients with $R E$ is highlighted.

\section{REFERENCES}

1. Andermann F: Chronic encephalitis and epilepsy: Rasmussen's syndrome. Butterworth-Heinemann, 1991

2. Bien CG, Granata T, Antozzi C, Cross JH, Dulac O, Kurthen M, Lassmann H, Mantegazza R, Villemure JG, Spreafico $\mathrm{R}$, Elger CE: Pathogenesis, diagnosis and treatment of Rasmussen encephalitis: A European consensus statement. Brain 128(3):454-471, 2005

3. Bien CG, Schramm J: Treatment of Rasmussen encephalitis half a century after its initial description: Promising prospects and a dilemma. Epilepsy Res 86(2-3):101-112, 2009

4. Bien CG, Tiemeier $H$, Sassen R, Kuczaty $S$, Urbach $H$, Lehe MV, Becker AJ, Bast T, Herkenrath P, Karenfort M: Rasmussen encephalitis: Incidence and course under randomized therapy with tacrolimus or intravenous immunoglobulins. Epilepsia 54(3):543-550, 2013

5. Bulteau C, Grosmaitre C, Save-Pédebos J, Leunen D, Delalande O, Dorfmüller G, Dulac O, Jambaqué I: Language recovery after left hemispherotomy for Rasmussen encephalitis. Epilepsy Behav 53:51-57, 2015

6. Geller E, Faerber EN, Legido A, Melvin JJ, Hunter JV, Wang Z, de Chadarevian JP: Rasmussen encephalitis: Complementary role of multitechnique neuroimaging. AJNR Am J Neuroradiol 19(3): 445-449, 1998

7. Jay V, Becker LE, Otsubo H, Cortez M, Hwang P, Hoffman HJ, Zielenska M: Chronic encephalitis and epilepsy (Rasmussen's encephalitis) Detection of cytomegalovirus and herpes simplex virus 1 by the polymerase chain reaction and in situ hybridization. Neurology 45(1):108-117, 1995 
8. Korn-Lubetzki I, Bien CG, Bauer J, Gomori M, Wiendl H, Trajo L, Ovadia H, Wilken B, Hans VH, Elger CE, Hurvitz H, Steiner I: Rasmussen encephalitis with active inflammation and delayed seizures onset. Neurology 62(6):984-986, 2004

9. Lamb K, Scott WJ, Mensah A, Varadkar S, Robinson R, Cross $\mathrm{HJ}$ : Incidence, prevalence and clinical outcome of Rasmussen Encephalitis in children from the United Kingdom. Epilepsia 54 Suppl 3:4, 2013

10. Power C, Poland SD, Blume WT, Girvin JP, Rice GP: Cytomegalovirus and Rasmussen's encephalitis. Lancet 336(8726): 1282-1284,1990

11. Rasmussen T, Olszewski J, Lloydsmith D: Focal seizures due to chronic localized encephalitis. Neurology 8(6):435-445, 1958

12. Rogers SW, Andrews PI, Gahring LC, Whisenand T, Cauley K, Crain B, Hughes TE, Heinemann SF, McNamara JO: Autoantibodies to glutamate receptor GluR3 in Rasmussen's encephalitis. Science 265(5172):648-651, 1994
13. Villemure JG, Daniel RT: Hemispherectomy. Springer: Berlin Heidelberg, 2009

14. Vinters HV, Wang R, Wiley CA: Herpes viruses in chronic encephalitis associated with intractable childhood epilepsy. Hum Pathol 24(8):871-879, 1993

15. Vora N, Cross JH, Robinson R: Epilepsy surgery in Rasmussen Syndrome. Epilepsy Currents 12 Suppl 1:2.296, 2012

16. Walter GF: Epstein-Barr virus in brain and Rasmussen's encephalitis, Lancet 1(8632): 279-280, 1989

17. Watson R, Jiang Y, Bermudez I, Houlihan L, Clover L, McKnight K, Cross JH, Hart IK, Roubertie A, Valmier J, Hart Y, Palace J, Beeson D, Vincent A, Lang B: Absence of antibodies to glutamate receptor type 3 (GluR3) in the sera of patients with Rasmussen's encephalitis. Neurology 63(1): 43-50, 2004 